\title{
The Incidence and Distribution of Colicinogenic and Colicin-sensitive Escherichia coli in the Gastro-intestinal Tract of the Pig
}

\author{
By M. C. L. DE ALWIS AND J. R. THOMLINSON \\ Department of Veterinary Pathology, University of Liverpool, Liverpool, L69 $3 B X$
}

(Received 28 June 1972)

\begin{abstract}
SUMMARY
Eleven Escherichia coli serotypes recognized as being pathogenic for the pig and 23I commensal strains of $E$. coli from pigs were examined for colicinogeny and colicin sensitivity. Of the commensal strains, $43.7 \%$ were colicinogenic, and produced I I known colicins and others that could not be identified. The only pathogenic strains shown to be colicinogenic were those of the or4I serogroup which produced colicin $B$.

All the pathogenic strains were sensitive to colicins produced by the commensal strains. The implications of these findings are discussed in relation to the dominance of pathogenic serotypes in colibacillosis.
\end{abstract}

\section{INTRODUCTION}

Relatively few investigations have been made into the colicinogenic properties of Escherichia coli from the gastro-intestinal tract of the pig. Levine \& Tanimoto (1960) observed that colicinogenic strains were present in $83.7 \%$ of the pigs they investigated. More recently, Vasenius (1967) found a higher incidence of colicinogenic $E$. coli in pigs suffering from colibacillosis than in normal animals and concluded that the ability to produce colicin may be at least a contributory factor in the preservation of potentially pathogenic serotypes among the intestinal flora of healthy pigs. On the other hand, Craven, Miniats \& Barnum (197I) concluded from their experiments with dual-infected gnotobiotic pigs that colicin production did not appear to influence bacterial antagonism in the alimentary tract and that other factors such as the differential growth rates of individual strains were probably responsible. A strain of $E$. coli producing an unidentified colicin was capable of dominating colicin-resistant mutants and a non-colicinogenic strain was capable of dominating certain colicin-sensitive strains.

The present work formed part of an investigation into factors that may lead to the dominance of pathogenic Escherichia coli strains in the gastro-intestinal tract of the pig. Colicins were identified and sensitivity patterns were investigated in commensal and pathogenic strains with a view to determining whether colicins may play any part in the stabilization of the coliform enteric flora.

$$
\text { MATERIALS }
$$

Sources of commensal Escherichia coli

A total of 23I strains from healthy pigs derived from two sources were isolated on $5 \%$ sheep blood agar. All these strains possessed the characteristic biochemical features of Escherichia coli and, since they failed to type with antisera to any of the recognized porcine 
Table I. Colicin sensitivity of the standard indicator strains of Escherichia coli

\begin{tabular}{|c|c|c|c|c|c|c|c|c|c|c|}
\hline \multirow{2}{*}{$\begin{array}{l}\text { Indicator } \\
\text { strain }\end{array}$} & \multicolumn{10}{|c|}{ Colicins } \\
\hline & A & B & $\mathrm{E}_{1}$ & $\mathrm{E}_{2}$ & $\mathrm{E}_{3}$ & G & I a & Ib & $\mathbf{K}$ & $\mathrm{V}$ \\
\hline CLI42 & $\mathbf{S}$ & $\mathbf{S}$ & $\mathbf{S}$ & $\mathbf{S}$ & $\mathrm{S}$ & $\mathbf{S}$ & $\mathbf{S}$ & $\mathbf{S}$ & $S$ & $\mathbf{S}$ \\
\hline CLI36 & $\mathbf{R}$ & $\mathbf{S}$ & $\mathbf{R}$ & $\mathbf{S}$ & $\mathbf{S}$ & $\mathbf{S}$ & $\mathbf{S}$ & $\mathbf{S}$ & $\mathbf{S}$ & $\mathbf{S}$ \\
\hline CLI 35 & $\mathbf{S}$ & $\mathbf{R}$ & $\mathbf{S}$ & $\mathbf{S}$ & $\mathbf{S}$ & $\mathbf{S}$ & $\mathbf{S}$ & $\mathbf{S}$ & $\mathbf{S}$ & $\mathbf{R}$ \\
\hline CLI 37 & $\mathbf{S}$ & S & $\mathrm{S}$ & $\mathrm{R}$ & $\mathrm{S}$ & $\mathbf{S}$ & $\mathbf{S}$ & $\mathrm{S}$ & $\mathbf{S}$ & $\mathrm{S}$ \\
\hline CLI45 & $\mathrm{s}$ & $\mathbf{S}$ & $\mathbf{R}$ & $\mathbf{R}$ & $\mathrm{R}$ & $\mathbf{S}$ & $\mathrm{S}$ & $\mathbf{S}$ & $\mathbf{S}$ & $\mathrm{S}$ \\
\hline CLI44 & $\mathbf{S}$ & $\mathrm{R}$ & $S$ & $\mathbf{S}$ & $\mathrm{S}$ & $\mathrm{s}$ & $\mathbf{S}$ & $\mathbf{S}$ & $S$ & $\mathbf{S}$ \\
\hline CL223 & $\mathbf{S}$ & $\mathbf{S}$ & $\mathbf{S}$ & $\mathrm{S}$ & $\mathrm{S}$ & $\mathbf{S}$ & $\mathbf{R}$ & $\mathbf{S}$ & $\mathbf{S}$ & $\mathbf{S}$ \\
\hline $\mathrm{CL}_{232}$ & $\mathbf{S}$ & $\mathrm{S}$ & $\mathbf{S}$ & $\mathbf{S}$ & $\mathbf{S}$ & $\mathbf{S}$ & $\mathbf{S}$ & $\mathbf{R}$ & $\mathbf{S}$ & $\mathbf{S}$ \\
\hline CLI 46 & $\mathbf{R}$ & $\mathbf{S}$ & $\mathbf{S}$ & $\mathbf{S}$ & $\mathbf{S}$ & $\mathbf{S}$ & $\mathbf{S}$ & $\mathbf{S}$ & $\mathrm{R}$ & $\mathbf{S}$ \\
\hline CL2O5 & $\mathrm{S}$ & S & $\mathbf{S}$ & $\mathbf{S}$ & $\mathbf{S}$ & $\mathrm{S}$ & $\mathrm{R}$ & $\mathbf{R}$ & $\mathrm{S}$ & $\mathbf{R}$ \\
\hline CLI 84 & $\mathbf{S}$ & $\mathbf{S}$ & $\mathrm{R}$ & $\mathbf{S}$ & $\mathbf{S}$ & $S$ & $\mathrm{R}$ & $\mathbf{R}$ & $\mathrm{S}$ & $\mathrm{S}$ \\
\hline CL2OI & $\mathbf{R}$ & $\mathbf{S}$ & $\mathbf{R}$ & $\mathbf{R}$ & $\mathrm{R}$ & $\mathbf{S}$ & $\mathbf{S}$ & $\mathbf{S}$ & $\mathbf{S}$ & $\mathbf{S}$ \\
\hline
\end{tabular}

pathogenic serotypes, they were regarded as commensals.

Source $A$. One hundred non-haemolytic and 27 haemolytic strains were isolated from swabs taken from various regions of the gastro-intestinal tracts of 20 freshly slaughtered pigs at an abattoir in Liverpool.

Source B. Eighty-two non-haemolytic and 22 haemolytic strains were isolated from rectal swabs obtained from 70 weaned pigs selected at random from a large herd in Scotland.

\section{Sources of pathogenic Escherichia coli}

Eleven haemolytic Escherichia coli strains, kindly supplied by $\mathrm{Mr}$ W. J. Sojka and recognized as pathogenic for the pig, were examined for colicin production and sensitivity. These strains represented the following ' $O K$ ' groups-oI $4 \mathrm{I}: \mathrm{K} 85 \mathrm{a}, \mathrm{b}(\mathrm{B}), 88 \mathrm{a}, \mathrm{b}(\mathrm{L})$; oI4I :K85a, b(B); oI4I:K85a, c(B); oI4I :K85a, c(b), 88a, b(L); oI38:K8I (B); oI38: $\mathrm{K} 8 \mathrm{I}(\mathrm{B}), 88 \mathrm{a}, \mathrm{c}(\mathrm{L})$; 08:K 87(B ?), 88a, b(L); 08:K87(B ?), 88a，c(L); о $39: \mathrm{K} 82(\mathrm{~B})$; oI 47:K 79(B), 88a, c(L); and oI 49:K9I, 88a, c(L).

\section{Standard colicin-sensitive and colicinogenic strains}

Standard strains of Escherichia coli and Shigella having specific patterns of colicin sensitivity or known colicinogenic properties were kindly provided by Professor P. Fredericq and Dr M. J. Lewis. Table I shows the colicin sensitivity patterns of these various strains and their colicinogenic properties are shown in Table 2 . In addition, five indicator strains with specific patterns of colicin sensitivity were selected from the commensal $E$. coli isolated from pigs. Of these, strain $F 3$ was specifically sensitive to colicins D and F, F7 to colicins D and $\mathrm{J}$, FIo to colicin D only, F57 to colicins D and H, and CI 8 to colicins D and $\mathrm{S}_{3}$.

\section{Colicin tests}

The method was similar to that of Fredericq (I948). Spot cultures of up to eight strains to be tested for colicin production were made on nutrient agar plates $\left(\mathrm{pH}_{7} \cdot 4\right)$ in glass Petri dishes of $\mathrm{IO} \mathrm{cm}$ diameter. The cultures were incubated at $37^{\circ} \mathrm{C}$ for $24 \mathrm{~h}$, killed by exposure to chloroform vapour, incubated at $37^{\circ} \mathrm{C}$ for $30 \mathrm{~min}$ to remove any residual chloroform and flooded with a 6 to $8 \mathrm{~h}$ broth culture of an indicator strain. Excess broth was removed and, after incubation at $37{ }^{\circ} \mathrm{C}$ for a further $24 \mathrm{~h}$, the plates were examined for zones of inhibition. 
Table 2. Standard colicinogenic strains of Escherichia and Shigella

\begin{tabular}{|c|c|c|}
\hline $\begin{array}{c}\text { Source } \\
\text { Dr M. J. Lewis }\end{array}$ & $\begin{array}{c}\text { Strain } \\
\text { Escherichia coli }\end{array}$ & Colicin proc \\
\hline & $\begin{array}{l}\text { CLI23 } \\
\text { CLI2 I } \\
\text { CLI22 } \\
\text { CLI36 } \\
\text { CLI37 } \\
\text { CLI24 } \\
\text { CL126 } \\
\text { CL223 } \\
\text { CL232 } \\
\text { G I } 44, \text { G } 206 \\
\text { G } 275\end{array}$ & $\begin{array}{l}A \\
B \\
D \\
E_{1} \\
E_{2} \\
E_{3} \\
G \\
I a \\
I b \\
K \\
V\end{array}$ \\
\hline Professor P. Fredericq & $\begin{array}{l}\text { Escherichia coli } \\
\quad \text { CA57 } \\
\text { CA42 } \\
\text { CA58 } \\
\text { CA62 } \\
\text { Shigella boydii } \mathrm{PI} \\
\text { S. sonnei } \mathrm{P9} \\
\text { S. dispar PI4 } \\
\text { S. dispar PI5 }\end{array}$ & $\begin{array}{l}\mathrm{C} \\
\mathrm{F} \\
\mathrm{H} \\
\mathrm{J}+\mathrm{I} \\
\mathrm{S}_{1} \\
\mathrm{~S}_{3}+\mathrm{I} \\
\mathrm{S}_{4} \\
\mathrm{~S}_{5}\end{array}$ \\
\hline
\end{tabular}

Colicins $A, B, E\left(E_{1}, E_{2}\right.$ and $\left.E_{3}\right), G, I a, I b, K$ and $V$ were identified on the basis of the specific pattern of resistance of the indicator strains. Colicins $\mathrm{D}, \mathrm{F}, \mathrm{H}, \mathrm{J}$ and $\mathrm{S}_{3}$ were identified on the basis of specific sensitivity of indicator strains to these colicins.

Colicin sensitivity was determined by the use of similar tests with the standard colicinogenic strains, in which the Escherichia coli strains under investigation were used as indicators.

\section{RESULTS}

Incidence of colicinogenic Escherichia coli

Commensal strains. Of the $23 \mathrm{I}$ commensal strains tested, IOI $(43.7 \%)$ were colicinogenic. The colicins identified were A, B, E ( $E_{1}, E_{2}$ and $\left.E_{3}\right), F, G, H, I, J, K, S_{3}$ and V (Table 3), and were produced by 68 of the strains. Of these, colicin $E$ was the most common. The colicins produced by the remaining 33 colicinogenic strains could not be identified with the indicator strains available.

The percentage of colicinogenic strains isolated from the caecum, colon and rectum of source A was similar to that from the rectal swabs of source B (Table 3) but the small intestine of source A yielded a lower proportion of colicinogenic strains.

Pathogenic strains. Of the I I pathogenic Escherichia coli strains, only four, oI $4 \mathrm{I}: \mathrm{K} 85 \mathrm{a}$, b(B), 88 a, b(L), OI4I : K 85a, b(B), OI 4I :K 85a, c(B) and oI 4I :K 85a, c(B), 88a, b(L), were colicinogenic. Colicin $\mathrm{B}$ was produced by all four strains.

\section{Colicin sensitivity}

Commensal strains. Of the 23I commensal strains examined, 22 I $(95.6 \%)$ showed colicin sensitivity. Of these, 67 were sensitive to only one colicin. Of the remainder, 70 were sensitive to five or more colicins and two were sensitive to I4. No regularity was observed in the sensitivity pattern and the strains could not be classified into a reasonable number of groups on the basis of their sensitivity patterns. 

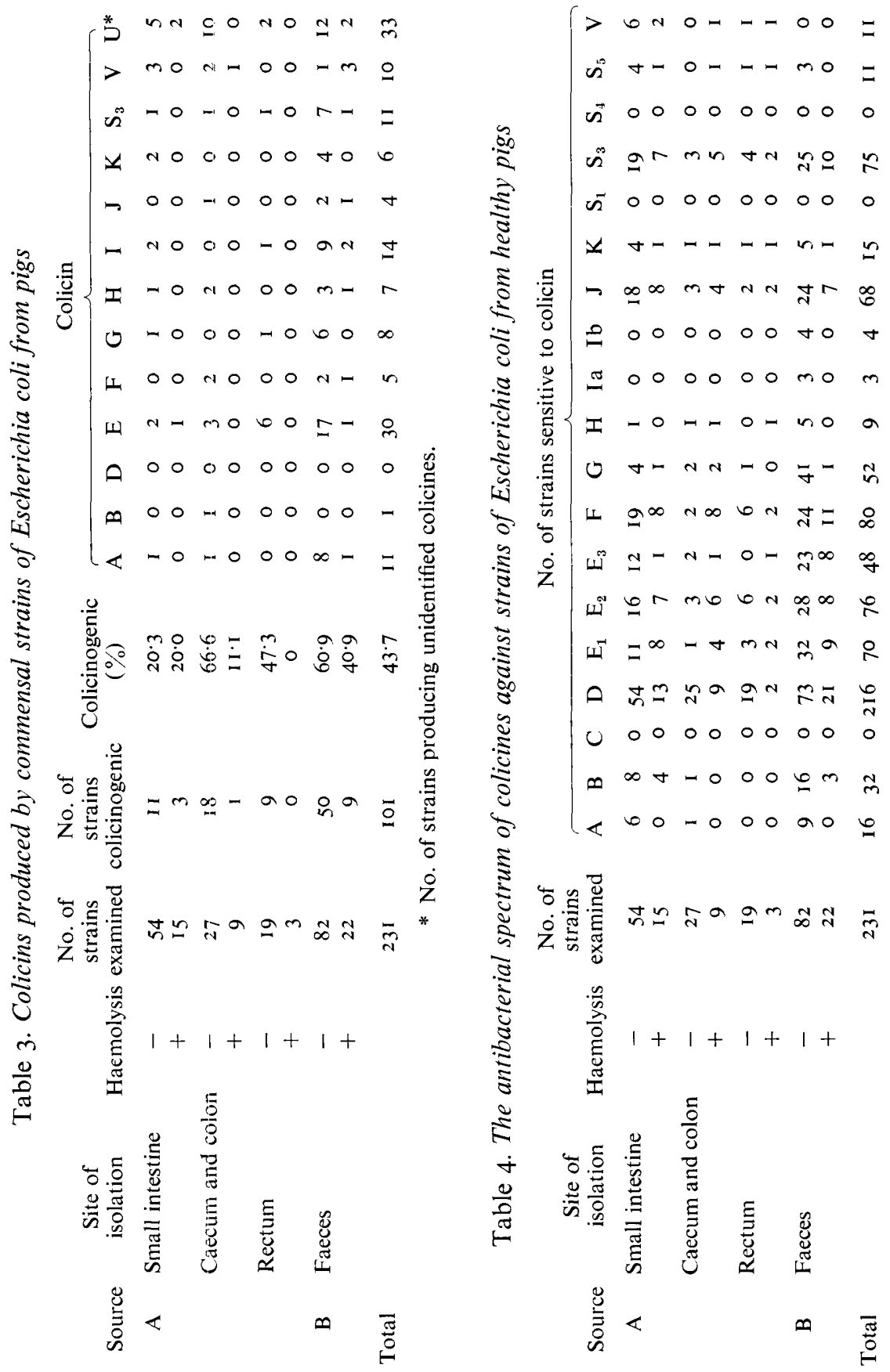
Colicin D showed the widest spectrum of activity and was active against $216(93.5 \%)$ of the 23I commensal Escherichia coli strains. Other colicins showed varying degrees of activity (Table 4 ). For instance, colicins $\mathrm{F}, \mathrm{E}_{2}, \mathrm{~S}_{3}, \mathrm{E}_{1}$ and $\mathrm{J}$ were active against $34 \cdot 6,32 \cdot 9,32 \cdot 4,30 \cdot 3$ and $29.4 \%$ of the commensal strains, respectively, while colicin B, which was the only one produced by any of the pathogenic serotypes, was active against only $13.8 \%$ of the commensal strains. Colicins $\mathrm{C}, \mathrm{S}_{1}$ and $\mathrm{S}_{4}$ showed no activity.

Pathogenic strains. Each of the eight pathogenic strains tested (Table 5) was sensitive to the action of at least two colicins. The widest range of sensitivity was shown by the strains of ' $\mathrm{O}$ ' group I4I. Two of these were sensitive or partially sensitive to ten colicins and the other was sensitive to nine. Escherichia coli strain O8:K87(B), 88a, b(L) showed the narrowest range, and was sensitive to colicins $D$ and $F$ and partially sensitive to colicin $E_{2}$.

Colicin D had the widest spectrum of activity. Seven of the eight pathogenic strains were sensitive to this colicin and the other was partially sensitive. Of the other colicins, $\mathrm{E}_{1}, \mathrm{E}_{2}$ and $F$ had the widest spectra of activity.

\section{DISCUSSION}

In these investigations, $43 \cdot 7 \%$ of commensal Escherichia coli strains from pigs were shown. to be colicinogenic, whereas the only pathogenic strains that showed colicinogenic activity were those of the OI4I group. Vasenius (1967) found that $59 \cdot 3 \%$ of E. coli strains isolated from pigs suffering from colibacillosis were colicinogenic, whereas only $17 \cdot 2 \%$ from healthy pigs showed this property.

Earlier reports on the incidence of colicinogenic bacteria in the faeces of man and various animal species have shown some variation. Gardner (I950) examined 3I 7 strains isolated mainly from human faeces and reported an incidence of II.6\% whereas Papavassiliou (I963) reported an incidence of $32 \cdot \mathrm{I} \%$ among Escherichia coli from human faeces, $28.6 \%$ from the dog, $26 \cdot 3 \%$ from sheep and relatively few from rats and mice. In the present investigation, the incidence of colicinogeny was lower among strains isolated from the small intestine than from the rectum. This finding was not surprising since Vosti (I 968) observed that, in human faeces, resident serotypes are more consistently colicinogenic than are transient ones and, according to Dixon (1960), the small numbers of organisms found in mammalian small intestines are transient, there being few resident organisms in this part of the intestine. However, it is clear that, at least in pigs, the site of isolation is important and results from the contents of the small intestine cannot be directly compared with those from the colon, rectum or faeces. The high incidence of colicinogeny observed in the commensal strains from pigs was consistent with the findings of Branche, Young, Robinet \& Massey (1963), who observed a high incidence of colicinogeny when the multiplicity of serotypes was high and a low incidence when few serotypes were present. Serological analysis of the commensal strains (de Alwis, 1970) had revealed considerable heterogenicity.

On the other hand, the high incidence of colicinogeny observed by Vasenius (1967) in strains from diseased pigs may have been a reflexion of the dominance of one particular serogroup. Although, in the present investigation, OI4I was the only serogroup to show colicinogeny, only one example of each pathogenic serotype was tested and Vasenius (I 967) observed a high incidence of colicinogeny in serogroups other than oI $4 \mathrm{I}$, especially when they had been isolated from diseased pigs. A similar high incidence of colicinogeny has been observed in pathogenic Escherichia coli serotypes from children and from calves (Papavassiliou, I96I; Likhoded \& Kudlai, 1963). Vosti (1968) has shown that individual strains within a serogroup may differ in their colicinogenic activity or in the colicin they produce, 


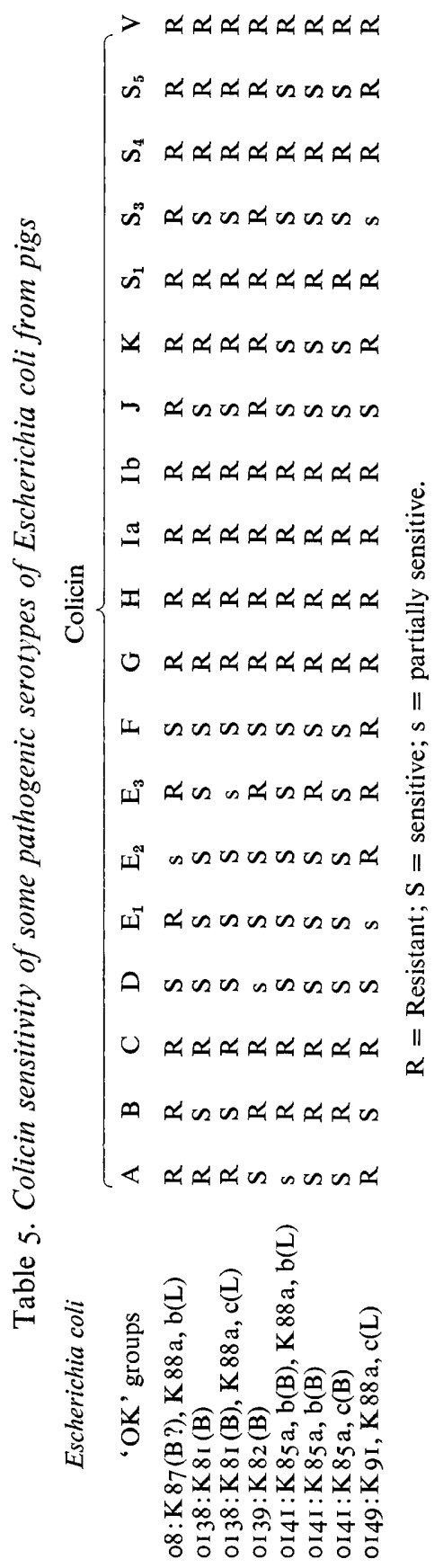


and it is possible that conditions favouring the multiplication of certain colicinogenic strains may also favour the transfer of episomes controlling colicinogeny (Braude \& Siemienski, I968). In experimental shigella infections, Halbert (I948) observed an increase in the number of antagonistic coliforms after infection had occurred. Clearly, the results of investigations in which relatively small numbers of strains have been examined, or have been derived from a highly selected source such as a single outbreak of disease, must be interpreted with caution, and further clarification of these mechanisms will necessitate the examination of a large number of individual strains of each pathogenic serotype from a wide variety of sources.

The question of whether colicins play any part in the stabilization of the enteric flora is also a subject of controversy. Much of the evidence (Halbert \& Swick, I950; Friedman \& Halbert, 1960; Braude \& Siemienski, 1968; Ikari, Kenton \& Young, 1969; Kelstrup \& Gibbons, 1969; Craven et al. 197I) suggests that they do not contribute significantly to selective advantage in the intestinal tract where they are probably inactivated by free trypsin (Gratia \& Betz-Bareau, 1946; Gardner, I950), but that they may be active in infections of the peritoneal cavity or the urinary bladder. Since they occur at significant levels in serum and local exudates (Halbert \& Swick, 1950), it is also possible that they may play a part in resistance to generalized infection.

A widely accepted feature in the pathogenesis of colibacillosis in pigs or other young animals is the dominance of one or other of the pathogenic Escherichia coli serotypes in the gastro-intestinal tract. The only colicin produced by any of the pathogenic serotypes tested in the present experiments was colicin B to which only a relatively small proportion of commensal strains was sensitive. However, all the pathogenic serotypes were sensitive to at least one of the colicins produced by commensal strains. These included I I of the known colicins and others that were not identified. Thus it would seem unlikely that a pathogenic serotype would assert dominance in the gastro-intestinal tract of the pig through the action of its colicin but, under suitable environmental conditions, colicins produced by commensal strains may be capable of exerting control on the population of pathogenic serotypes. Individual colicins differ in their susceptibility to trypsin (Gardner, 1950) and it is noteworthy that colicin $\mathbf{D}$, which has a wide spectrum of activity and is relatively resistant to trypsin, was not produced by any of the commensal strains from pigs. However, environmental conditions in the gastro-intestinal tract may differ in individual animal species and may also be influenced by diet. Whether conditions favourable to the action of colicins may occur in the gastro-intestinal tract of the pig is the subject of further investigation.

This work was carried out when one of us (M.deA.) was the holder of a Colombo Plan Fellowship and we wish to acknowledge the financial support of the British Council. Our thanks are due to Professor P. Fredericq, Dr M. J. Lewis and Mr W. J. Sojka who provided type cultures and to Mr D. McLauchlan who provided many samples. We are indebted to Professor D. L. Hughes for his helpful criticism and to Mrs J. J. Jones for technical assistance.

\section{REFERENCES}

DE ALwIS, M. C. L. (1970). Some factors influencing the survival and multiplication of pathogenic Escherichia coli in the gastro-intestinal tract of the pig. Ph.D. Thesis, University of Liverpool.

Branche, W. C., Jun., Young, V. M., Robinet, H. G. \& Massey, E. D. (1963). Effect of colicin production on Escherichia coli in the normal human intestine. Proceedings of the Society for Experimental Biology and Medicine I14, I98-20I.

Braude, A. I. \& Siemienski, J. S. (I968). The influence of bacteriocins on resistance to infection by Gramnegative bacteria. II. Colicin action, transfer of colicinogeny and transfer of antibiotic resistance in urinary infections. Journal of Clinical Investigation 47, I763-I 773. 
Craven, J. A., Miniats, O. P. \& Barnum, D. A. (197I). Role of colicins in antagonism between strains of Escherichia coli in dual-infected gnotobiotic pigs. American Journal of Veterinary Research 32, $1775^{-1} 779$.

Dixon, J. M. S. (1960). The fate of bacteria in the small intestine. Journal of Pathology and Bacteriology 79 , I 3 I-139.

FredericQ, P. (1948). Actions antibiotiques réciproques chez les Enterobacteriaceae. II. Les colicines et leurs récepteurs d'antibiose. Revue belge de pathologie et de médicine expérimentale I9, supplément IV, 3I-46.

Friedman, D. R. \& Halbert, S. P. (1960). Mixed bacterial infections in relation to antibiotic activities. IV. Shigella-Escherichia coli infections. Journal of Immunology 84, 11-19.

GARDNER, J. F. (1950). Some antibiotics formed by Bacterium coli. British Journal of Experimental Pathology 3I, IO2-III.

Gratia, A. \& Betz-Bareau, M. (1946). La pluralité des colicines et leur sensibilité variable a la trypsine et aux protéases microbiennes. Compte rendu des séances de la Société de biologie 140, 1248-125I

Halbert, S. P. (I948). The relation of antagonistic coliform organisms to shigella infections. II. Observations in acute infections. Journal of Immunology 6o, 359-379.

Halbert, S. P. \& Swick, L. S. (I950). In vivo antibiotic production by Escherichia coli. Journal of Immuno$\log y \mathbf{6 5}, 675-686$.

Ikari, N. S., Kenton, D. M. \& Young, V. M. (I969). Interaction in the germ-free mouse intestine of colicinogenic and colicin-sensitive microorganisms. Proceedings of the Society for Experimental Biology and Medicine $\mathbf{1 3 0}, \mathrm{I} 280-1284$.

Kelstrup, J. \& GibBons, R. J. (1969). Inactivation of bacteriocins in the intestinal canal and oral cavity. Journal of Bacteriology 99, 888-890.

Levine, M. \& TANimoto, R. H. (1960). Observations on colicine-producing strains of $E$. coli from man and hogs. Bacteriological Proceedings, pp. 77-78.

Likhoded, V. G. \& Kudlai, D. G. (I 963). Colicines of enteropathogenic E. coli and their typing according to the specificity of mutants resistant to them. Zhurnal mikrobiologii, epidemiologii $i$ immunobiologii 4 , 128-I 32.

Papavassiliou, J. (1961). Lysogeny and colicinogeny in Escherichia coli. Journal of General Microbiology 25, 409-4I 3 .

Papavassiliou, J. (1963). Colicinogenic enterobacteria in human and animal faeces. Zeitschrift fiur Hygiene und Infektionskrankheiten 149, I64-169.

VASENIUS, H. (1967). The colicinogenic properties of porcine Escherichia coli strains. Acta veterinaria scandinavica 8, 195-200.

Vosti, K. L. (1968). Production of and sensitivity to colicins among serologically classified strains of Escherichia coli. Journal of Bacteriology 96, 1947-1952. 